\title{
Methodical Approach to Forecasting the Intensification of Innovative Development of Regions Using the Mathcad Program
}

\author{
Olha Popelo ${ }^{1}$, Svitlana Tulchynska ${ }^{2}$, Nataliia Lagodiienko ${ }^{3}$, Michael A. Radin ${ }^{4}$, Artem Moskalenko \\ ${ }^{1}$ Chernihiv Polytechnic National University, Chernihiv, Ukraine \\ ${ }^{2}$ National Technical University of Ukraine "Igor Sikorsky Kyiv Polytechnic Institute", Kyiv, Ukraine \\ ${ }^{3}$ Mykolayiv National Agrarian University, Mykolayiv, Ukraine \\ ${ }^{4}$ Rochester Institute of Technology School of Mathematical Sciences, New York, USA \\ ${ }^{5} \mathrm{IHE}$ “Academician Yuriy Bugay International Scientific and Technical University”, Kyiv, Ukraine
}

Received: April 5, 2021. Received: September 26, 2021. Accepted: October 15, 2021. Published: October 25, 2021.

\begin{abstract}
The authors have improved the methodical approach to assessing and forecasting the intensification of innovative development of regions, which contains a justification for the selection of statistical indicators of innovative development of regions, which are checked for compliance with the grouping by correlation analysis. The use of correlation analysis using Mathcad software makes it possible to eliminate autocorrelation relationships between selected assessment indicators of innovative development of regions. Confirmation of the weight of the grouping of evaluation indicators provides calculations of impact factors and determination of the most influential indicators on the integrated index of innovative development of regions using Mathcad software. The influence of the most influential indicators is also taken into account when forecasting the integrated index on the basis of estimated indicators using the Bartlett method. Predictive values and calculations of the integrated index of innovative development can be used in the practice of local and regional authorities to develop effective measures to enhance the intensification of innovative development of regions, taking into account the most influential factors for a particular region. The proposed methodological approach to forecasting innovative development was tested on the example of Polish regions, all calculations were performed using Mathcad software. For a more thorough analysis, three different voivodeships of Poland were selected, which belong to the voivodeships with high, medium and low levels of innovative development, have different and most influential indicators on the value of the integrated index. Such voivodeships include KujawskoPomorskie, Pomeranian and Swiętokrzyskie. When forecasting with the use of Mathcad software, which makes it possible to eliminate errors in calculations, an increase in the average value of the integrated index of innovation development was obtained.
\end{abstract}

Keywords - Innovative development, intensification, integrated index, evaluation, forecasting, region, regional economic system, sustainable development, voivodeships.

\section{INTRODUCTION}

$T$ HE instability of national economic development in today's globalization, the crisis, which is also caused by the COVID-19 pandemic, increasingly raises the issue of research to assess the intensification of innovative development of regional systems and their forecasting using Mathcad software to further develop measures to enhance regional development in innovation. Forecasting innovative development makes it possible to reduce bifurcations and trends in the development of regional economic systems and ensure a synergistic effect of innovation in relation to regional development.

One of the urgent problems in assessing and forecasting economic systems of different levels is the lack of accuracy of calculations. According to the authors, Mathcad software should be used to level the error and increase the accuracy of calculations and forecasts. Also, ensuring high accuracy in the calculation of innovative development and its forecasting requires the use of various methods of mathematical analysis and their combination. The combination of different methods in the calculations makes it possible to eliminate the shortcomings inherent in each of the methods and ensure higher quality and accuracy of the results. This, in turn, not only contributes to more accurate results, but also increases the efficiency of management decisions aimed at increasing the innovation activity of economic systems.

The accuracy of the obtained calculations is also affected by the time period of sampling of evaluation statistics. In our case, a sample for 10 years from 2010 to 2019 was made for the study. This time lag of the statistical data sample makes it possible to increase the verification of the forecast. Also, one of the techniques used by the authors to increase the 
verification of forecast data is the application of determining the most influential indicators through correlation analysis, as well as the use of the Bartlett method in forecasting. The combination of such methods of economic and mathematical modeling in assessing and forecasting the intensification of innovative development of regions makes it possible to model the behavior of the system with high accuracy. In turn, the use of the Bartlett method makes it possible to:

- get visualization of calculations and dynamic changes in indicators selected to assess the innovative development of regions, calculated integrated indices and their forecast values;

- increase the validity of the study of such complex systems as the region;

- identify changes in the processes that accompany the intensification of innovative development of regions and highlight their impact on the resulting indicator of innovative development, which is an integrated index of innovative development;

- identify the factors that most affect the development of the system and focus on their changes;

- if necessary, change the input parameters of the studied system, which makes it possible to unambiguously interpret the results of calculations of integrated indices of innovative development and their forecasting.

This makes it possible to increase the verification of the received forecast and estimated calculations of innovative development of the regions.

\section{II.LITERATURE REVIEW}

Domestic and foreign scientists are actively researching the issues of innovative development of regions, including: Abramova A. (2021) [1], Arinas R.J.S. (2020) [2], Bezrukova T.L., Gyiazov A.T. (2016) [3], Chernova V. (2020) [4], Dergaliuk B., Kreidych I. (2021) [5], Dubyna M. (2016) [6], Firsova A.A., Tsypin A.P. (2021) [7], Garafonova, O., Kovalska, L. (2021) [8]; Hajek P., Henriques R. (2019) [9], Kholiavko N. (2015) [10], Ključnikov A., Civelek M. (2020) [11], Kosach I., Duka A. (2020) [12], Lazarenko I., Saloid S. (2020) [13], Malik K., Jasińska-Biliczak A. (2018) [14], Marhasova V. (2021) [15], Nevezhin V.P., Zhiglyaeva A.V. (2019) [16], Plechero M., Chaminade C. (2016) [17], Revko A., Butko M. (2020) [18], Satya Shah (2019) [19], Shkarlet S., Ivanova N. (2020) [20], Sukhovey A.F., Golova I.M. (2020) [21], Vertakova Y., Risin I. (2020) [22], Viknianska A. (2021) [23], Vovk, O., Kravchenko M. (2021) [24]; Zajkowska M. (2017) [25] Zhavoronok A. (2020) [26] and others.

The study of Sukhovey A.F, Golova I.M is based on the development of a differentiated approach to the formation of strategies for innovative development of regions, which takes into account the parametric characteristics of scientific and technical, innovation and production activities and technological potential of the regions [21]. The aim of the article by Swedish researchers is to compare the model of cooperation for innovation in the Swedish, Norwegian, Chinese and Indian regions specializing in ICT, taking into account the characteristics of global innovation [17]. The authors A. Firsova and A. Tsypin claim that the research results can be useful for the development of regional innovation strategies and for further development of innovations [7].

Well-known Polish scientists study how innovations affect the competitiveness and sustainable development of small and medium enterprises [14]. Scientists Vertakova Yu., Risin I., Treshchevsky Yu., Klimov N. in their research study the features and threats to the development of innovative economy [22]. The research of Russian scientists is based on the development of models for forecasting the level of innovative development of countries with the identification of the most influential indicators that affect innovative development [16]. Arinas R.'s article analyzes the first regional laws concerning the circular economy to determine whether they are innovative [2]. Scientific research Civelek M., Krajcik V., Ondrejmiskova I. gives an assessment of the potential of innovative regional development of a structurally unfavorable industrial region [11].

Polish scientist Zajkowska M. argues that the reason for significant changes in the approach to innovation is the growing pace of technological progress, hypercompetitiveness and variability of markets, which are characteristic of the current stage of development of society [25]. Scientists from the Czech Republic and Portugal have developed a model for solving the problem of regional forecasting of innovation indicators, as scientists believe that this plays a key role in implementing policies aimed at supporting innovation [9]. Leading scientists Bezrukova T., Gyiazov A., Bazieva A. study the features, prospects and problems of improving the forecasting of innovative development of business structures in conditions of global competition [3].

\section{METHODICAL APPROACH}

Today there is a great variety of methodological approaches to assessing and forecasting the intensification of innovative development of regional economic systems. But, as previous research has shown, they are not based on the use of Mathcad software. This and other things require the improvement of the methodological approach to assessing and forecasting the intensification of innovative development of regions in order to increase the objectivity and accuracy of calculations, which affects the effectiveness of further management decisions aimed at innovative development of regions.

To assess and forecast the intensification of innovative development of the regions using the Mathcad program, the authors have developed an algorithm of actions, which provides the following sequence (Fig. 1). 


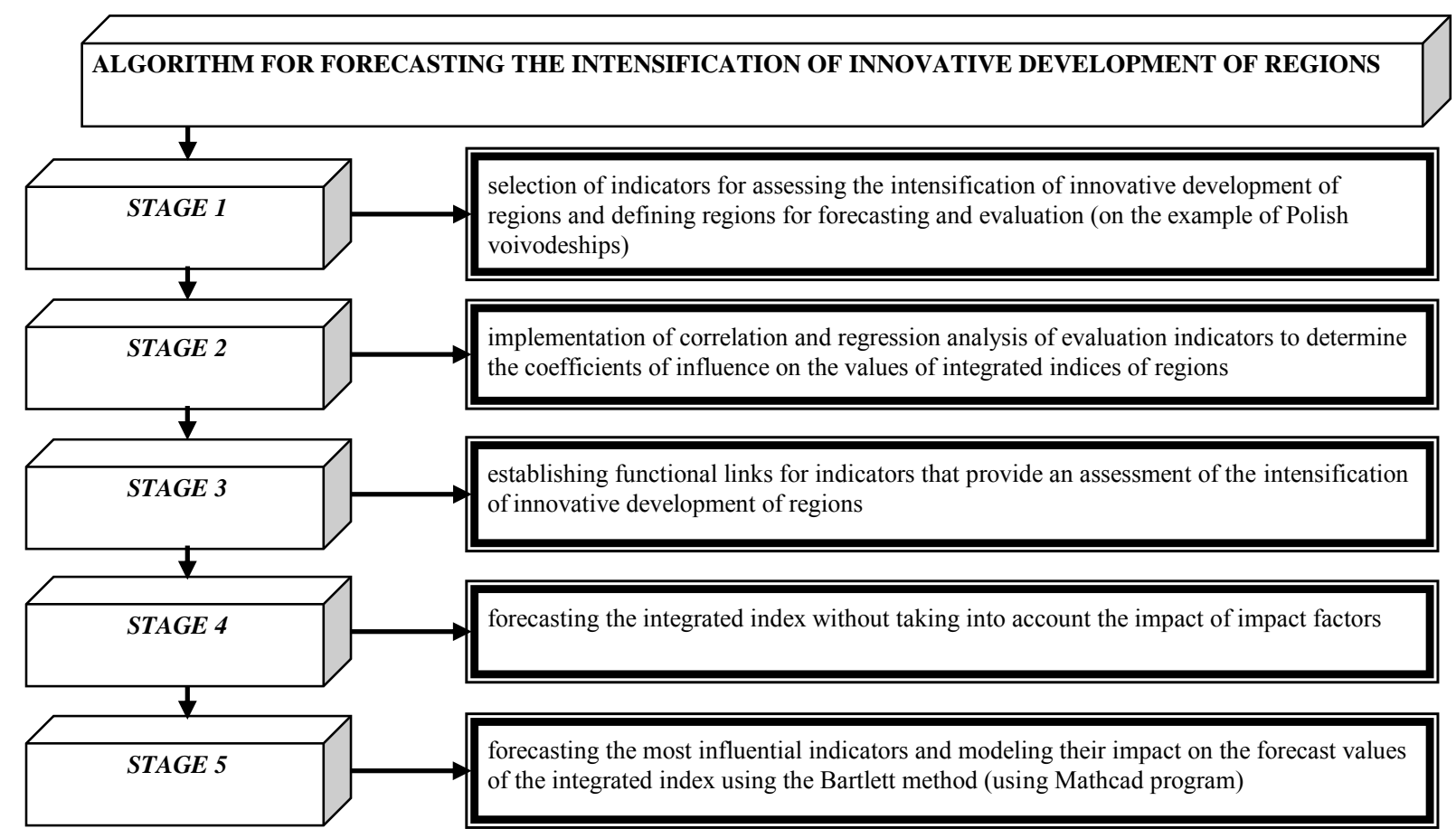

Fig. 1 Algorithm for forecasting the intensification of innovative development of regions using the Mathcad program Source: developed by the authors

Integrated indices are used to assess and forecast the intensification of innovative development of regions. The definition of integrated indices has such important positive features as the elimination of possible autocorrelation relationships between the estimated indicators of innovative development of regions. As already mentioned in this study, four evaluation indicators of innovative development at the regional level were used, but if necessary, the composition of evaluation indicators may change and expand depending on changes in the objectives of evaluation and forecasting. The use of Mathcad software in calculations makes it possible to calculate matrices of pair correlations and coefficients of influence on the integrated index of innovative development with high accuracy and to remove possible existing linear dependencies, the presence of which does not allow finding matrix calculations. Calculations of the coefficients of influence of the most influential evaluation indicators will increase the accuracy and reduce the error in the calculations and forecasting of innovative development of the regions.

Built-in functions in the Mathcad software provide input control of evaluation data, which is carried out at the level of the pairwise correlation, provided that $|\mathrm{k}| \geq 0.7$.

Those indicators in which the modulus correlation is less than $|\mathrm{k}|$ are used for further calculations of integrated indices of intensification of innovative development of regions. Such operations are conducted and repeated for each year in each region. Mathcad software makes it possible to calculate integrated indices for each year, but since the time horizon was chosen within 2010-2019, simulation is used to improve the accuracy of calculations. Simulation should be used when working with a large array of statistics, as in this case. Simulation modeling makes it possible to identify the behavior of the system when changing certain parameters of its development, which is represented, in our case, by the innovative development of regions. The main variables in simulation are the largest coefficients of influence on the value of the integrated index. Taking into account the impact factors makes it possible to predict the behavior of the system in the future by finding forecast data, as well as to identify areas of change.

The use of Mathcad software makes it possible to estimate the regression model, which involves regression and forecasting the intensification of innovative development of the regions through the given scenarios of the system. This provides high accuracy in modeling the impact of parameters, taking into account their coefficients of influence on the values of the projected integrated indices of intensification of innovation development.

The use of a multiple regression model provides the identification of the dependences of the existence of such a model. However, it is not always possible to build a model of multiple regression, because not every set of indicators has structural relationships between these features $X=\left(x^{(l)}, x^{(2)}, \ldots x^{(p)}\right)^{T}$. This means that not all selected parameters in the form of statistical evaluation indicators make it possible to fully describe and determine the characteristic manifestations of the system. Namely, to determine the influence on such general factors of system development $f^{(1)}, \ldots, f^{\left(p^{\prime}\right)}$, or to prove their existence, which are able to explain the existing correlation between pairs of features $\mathrm{x}^{(\mathrm{i})}, \mathrm{x}^{(\mathrm{i})}$ within a given statistical sample $v$. In the form of formulas, this can be described as follows:

$$
X=Q^{*} F+U
$$




$$
\mathrm{x}_{\mathrm{v}}^{(\mathrm{i})}=\sum_{\mathrm{j}=1}^{\mathrm{p}^{\prime}} \mathrm{f}_{\mathrm{v}}^{(\mathrm{j})} \mathrm{q}_{\mathrm{ij}}+\mathrm{u}_{\mathrm{v}}^{(\mathrm{i})}, \mathrm{i}=1, \ldots, \mathrm{p} ; \mathrm{v}=1, . ., \mathrm{n},
$$

where $v$ - the test number.

If the indicators chosen for evaluatioman and prediction allow to build multiple regression models, then the separation of the relevant factors $F^{T}=\left(f^{(1)}, \ldots, f^{\left(p^{\prime}\right)}\right)$ and coefficients of linear transformation $Q=\left(q_{i j}\right)$, which connects $X$ and $F$, is unique.

This, in turn, presupposes certain requirements $Q$ for the transformation matrix and the covariance matrix $V=\left(v_{i j}\right)$ of residual specific factors $u^{(1)}, \ldots, u^{(p)}$, since the definition of the parameters of the multiple regression model that we define must be unique.

The use of Mathcad software makes it possible to use the Bartlett method to predict the intensification of innovative development of regions. Bartlett's method separately for each fixed observation $v(v=1,2, \ldots, n)$ considers the econometric model as a regression $x_{v}$ of the sign by arguments $\hat{q}_{.1}, \hat{q}_{.2}, \ldots, \hat{q}_{\cdot p^{\prime}}$.

Mathcad provides the use of the least squares method, which determines the calculated impact factors to minimize the function, which has the form:

$$
\sum_{i=1}^{p} \frac{1}{\sigma_{i i}}\left(x_{v}^{(i)}-\sum_{j=1}^{p^{\prime}} \hat{f}_{v}^{(j)} \hat{\mathrm{q}}_{i j}\right)^{2}=\min _{F_{v}} \sum_{i=1}^{p} \frac{1}{\sigma_{i i}} \times\left(x_{v}^{(j)}-\sum_{j=1}^{p^{\prime}} f_{v}^{(j)} \hat{q}_{i j}\right)^{2}
$$

Therefore, we obtain regression relations in the form:

$$
\hat{\mathrm{F}}_{\mathrm{v}}=\left(\hat{\mathrm{Q}}^{\mathrm{T}} \hat{\mathrm{V}}^{-1} \hat{\mathrm{Q}}\right)^{-1} \hat{\mathrm{Q}}^{\mathrm{T}} \hat{\mathrm{V}}^{-1} \mathrm{X}_{\mathrm{v}}(v=1, \ldots, n)
$$

With a normal distribution of the values of the variables $X$, the calculated values of the mathematical expectations will be optimal. Taking into account the substitution of values $q_{i j}$ and $v_{i i}$ approximation of values $\hat{q}_{i j}$ and $\hat{v}_{i i}$ estimates of coefficients of influence $f^{(1)}, \ldots, f^{\left(p^{\prime}\right)}$ on the intensification of innovative development of regions are calculated.

The following relations in formulas 3 and 4 are used by the Bartlett method in the construction of matrices, and have the following form:

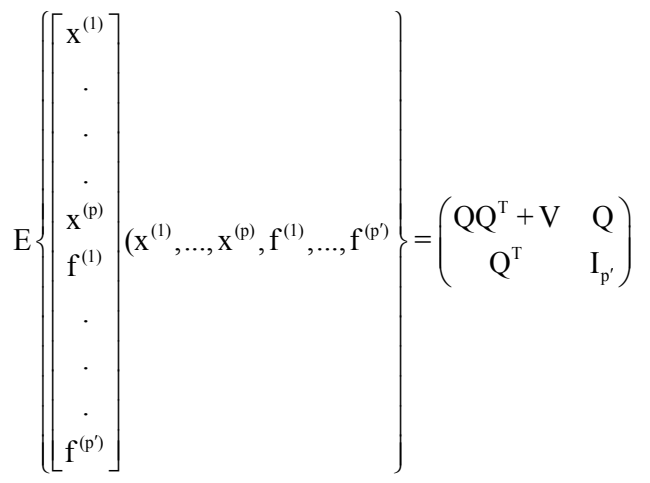

Using Mathcad software in the process of building the model uses mathematical and statistical formalization of evaluation indicators that affect the integrated index of innovative development of regions.

\section{THE RESULTS OF FORECASTING THE INTENSIFICATION OF INNOVATIVE DEVELOPMENT OF REGIONS}

The estimated initial data selected for the calculation of integrated indices and forecasting the intensification of regional innovations on the example of the Polish

\begin{tabular}{|c|c|c|c|c|}
\hline \multirow{2}{*}{\multicolumn{2}{|c|}{ Years }} & \multicolumn{3}{|c|}{ Indicator } \\
\hline & & $\mathbf{X 1}$ & $\mathbf{X} 2$ & \multirow[t]{2}{*}{$\mathbf{X} 4$} \\
\hline \multicolumn{4}{|c|}{ Kujawsko-Pomorskie Voivodeship } & \\
\hline 2010 & 331 & 1943,5 & 15,93 & 327,50 \\
\hline 2011 & 349 & 835,2 & 6,76 & 197,88 \\
\hline 2012 & 329 & 973,3 & 7,60 & 197,65 \\
\hline 2013 & 260 & 1010,9 & 7,75 & 197,48 \\
\hline 2014 & 295 & 1170,7 & 9,09 & 339,49 \\
\hline 2015 & 304 & 1645,3 & 12,62 & 290,98 \\
\hline 2016 & 345 & 1048,9 & 8,50 & 235,31 \\
\hline 2017 & 338 & 1109,0 & 7,66 & 265,41 \\
\hline 2018 & 458 & 1043,1 & 6,9 & 219,07 \\
\hline 2019 & 331 & 1943,5 & 15,93 & 213,93 \\
\hline \multicolumn{5}{|c|}{ Pomorskie Voivodeship } \\
\hline 2010 & 309 & 8332,9 & 49,76 & 672,9 \\
\hline 2011 & 313 & 8993,6 & 47,80 & 399,6 \\
\hline 2012 & 214 & 9585,0 & 46,85 & 318,3 \\
\hline 2013 & 315 & 4395,6 & 23,57 & 318,7 \\
\hline 2014 & 350 & 6046,7 & 31,76 & 455,8 \\
\hline 2015 & 315 & 3520,4 & 21,01 & 462,7 \\
\hline 2016 & 346 & 2298,6 & 13,50 & 497,5 \\
\hline 2017 & 376 & 2555,6 & 13,30 & 568,2 \\
\hline 2018 & 553 & 2522,8 & 12,2 & 503,7 \\
\hline
\end{tabular}
voivodeships are given in Table 1.

Table. 1. Indicators for assessing the innovative development of polish voivodeships 


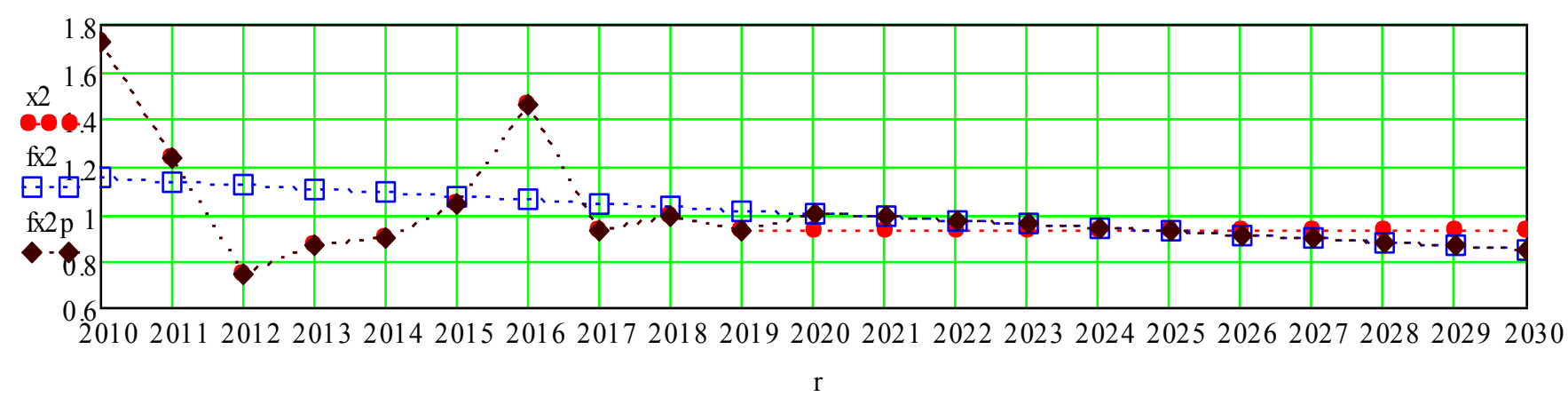

Fig. 3 Visualization of the dynamics of the most influential indicator and its forecast values for Kujawsko-Pomorskie Voivodeship (20102019 - retrospective period, 2020-2030 - forecast period)

Source: calculated by the authors using the Mathcad program

In Figure 4 presents the calculated and forecast values of the integrated innovation index of Kujawsko-Pomorskie Voivodeship. However, under the proposed methodological approach to forecasting, it should be noted that to increase the accuracy of calculations and take into account the impact of factors of different nature in forecasting, it is advisable to take into account the impact of indicators that have the greatest impact on the integrated index.

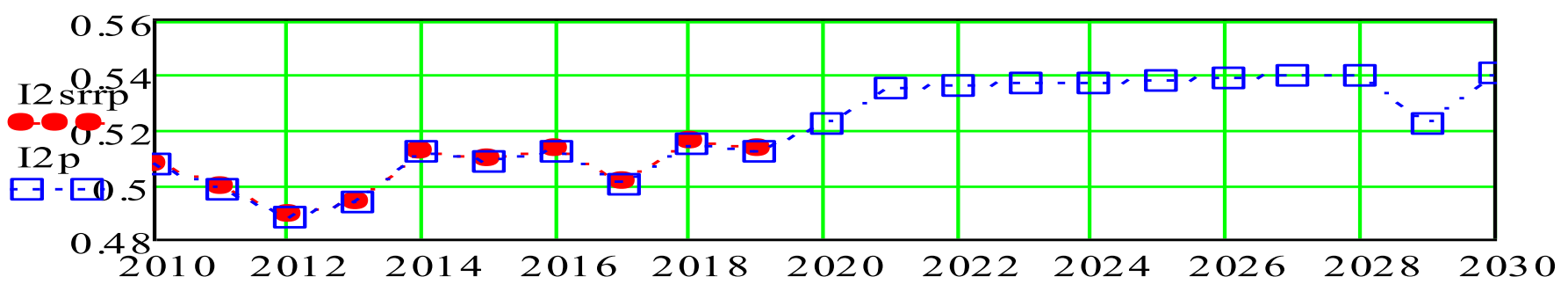

Fig. 4 Visualization of the dynamics of the integrated index and its forecast values for Kujawsko-Pomorskie Voivodeship (20102019 - retrospective period, 2020-2030 - forecast period)

Source: calculated by the authors using the Mathcad program

In Figure 5 presents the results of the calculated integrated indices for 2010-2019 and its forecast values for KujawskoPomorskie Voivodeship, taking into account the impact of the most influential indicator on the value of the integrated index. It should be noted that in general, changes in the average forecast integrated index, taking into account the emphasis on increasing the volume of sold innovative products will increase the average integrated index for the forecast period by 0.015 .

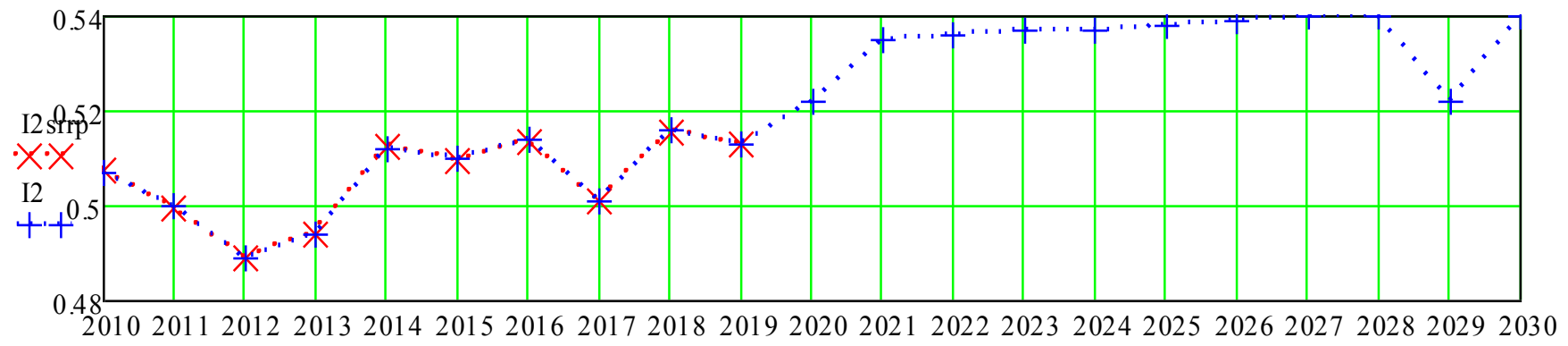

$r$

Fig. 5 Visualization of the dynamics of the integrated index and its forecast values for Kujawsko-Pomorskie Voivodeship (20102019 - retrospective period, 2020-2030 - forecast period)

Source: calculated by the authors using the Mathcad program

The average value of the calculated integrated index for 2010-2019 for Kujawsko-Pomorskie Voivodeship is 0.506, the average value of the projected integrated index is 0.535 .
In Figure 6-9 presents the results of calculations and forecasting of the integrated index and the most influential indicator which for the Pomeranian Voivodeship is the volume 
of sold innovative products in $\%$ to the total volume of sold industrial products. The presented results of calculation of impact coefficients for Pomeranian Voivodeship on average had the following values: $\mathrm{KX} 3=-0.165 ; \mathrm{KX} 2=0.152 ; \mathrm{KX} 1$ $=-0.036 ; \mathrm{KX} 4=0.031$. Indicators $\mathrm{X} 3, \mathrm{X} 2, \mathrm{X} 1, \mathrm{X} 4$ appear in the order of decreasing influence on the integral index.

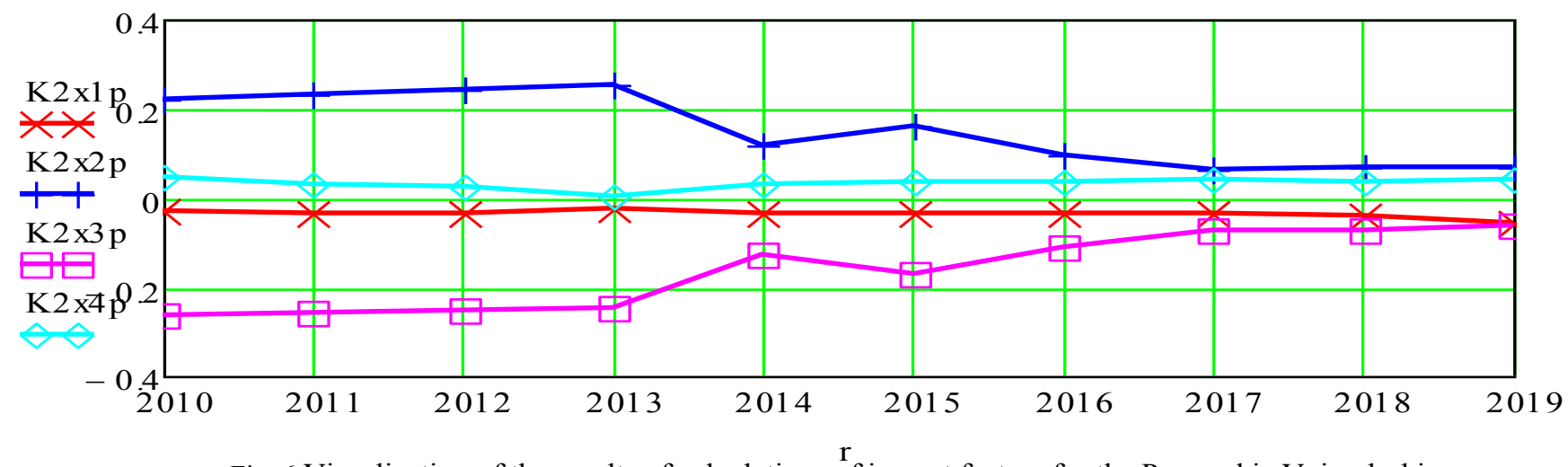

Fig. 6 Visualization of the results of calculations of impact factors for the Pomorskie Voivodeship

Source: calculated by the authors using the Mathcad program

The dynamics of the volume of sold products by industrial enterprises as a percentage of the total volume of sold industrial products in the form of analyzed normalized values of this indicator and projected for the period up to 2030 is presented in Figure 7.

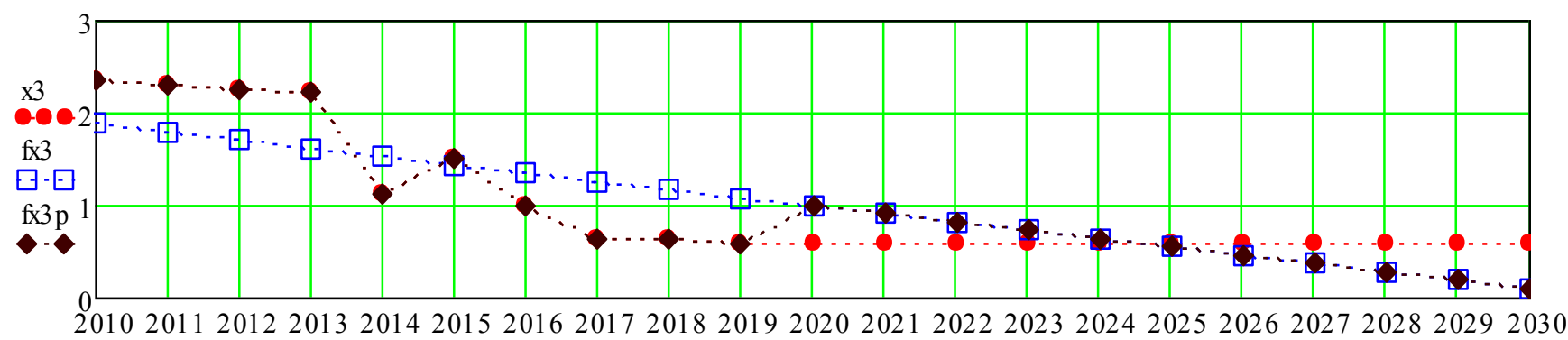

$r$

Fig. 7 Visualization of the dynamics of the most influential indicator and its forecast values for the Pomeranian Voivodeship (2010-2019 - retrospective period, 2020-2030 - forecast period)

Source: calculated by the authors using the Mathcad program

In Figure 8 presents the dynamics of the calculated and projected integrated innovation index of the Pomorskie
Voivodeship, the arithmetic mean value of the projected integrated index for $2020-2030$ is 0.855 .

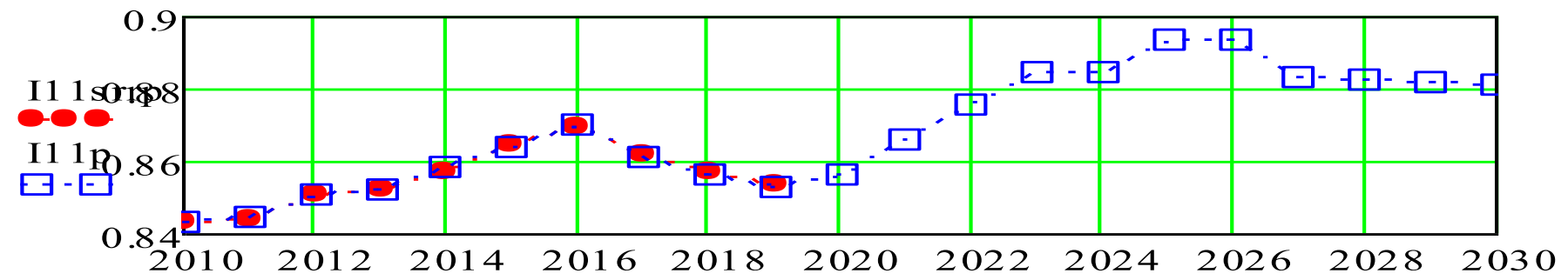

Fig. 8 Visualization of the dynamics of the integrated index and its forecast values for the Pomeranian (2010-2019 - retrospective period, 2020-2030 - forecast period)

Source: calculated by the authors using the Mathcad program

In Figure 9 presents the dynamics of the projected integrated index of innovation, taking into account the forecasting and determining the coefficient of influence of the most influential indicator on the value of the integrated index. 
It should be noted that the arithmetic mean of the projected integrated index for the Pomeranian Voivodeship is 0.869 , which is 0.014 more than the projected value of the integrated index of this voivodeship without taking into account the impact of the most influential indicator.

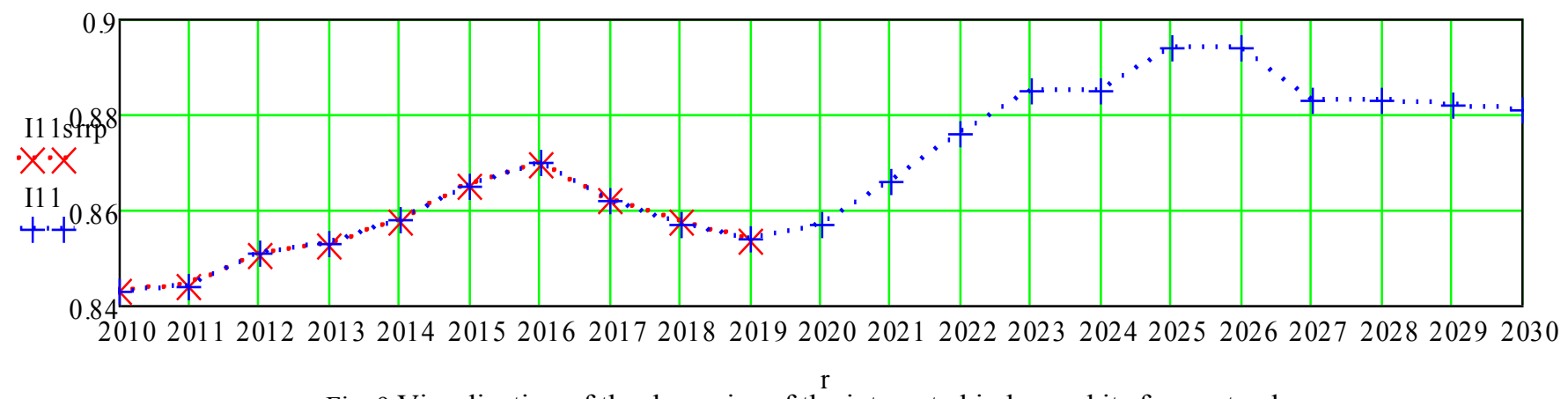

Fig. 9 Visualization of the dynamics of the integrated index and its forecast values for the Pomeranian Voivodeship (2010-2019 - retrospective period, 2020-2030 - forecast period)

Source: calculated by the authors using the Mathcad program

As already mentioned, the authors selected for a more detailed assessment of the proposed methodological approach three voivodeships with different values of the integrated index and different most influential indicators. The third voivodship is Swiętokrzyskie Voivodeship. Visualization of the most influential indicators on the integrated index of innovative development is presented in Figure 10.

Calculations of impact factors for Swiętokrzyskie Voivodeship on average had the following values: $\mathrm{KX} 1=-0.078 ; \mathrm{KX} 2=0.073 ; \mathrm{KX} 4=0.009 ; \mathrm{KX} 3=-0.001$. Indicators $\mathrm{X} 1, \mathrm{X} 2, \mathrm{X} 4, \mathrm{X} 3$ appear in the order of decreasing influence on the integral index.

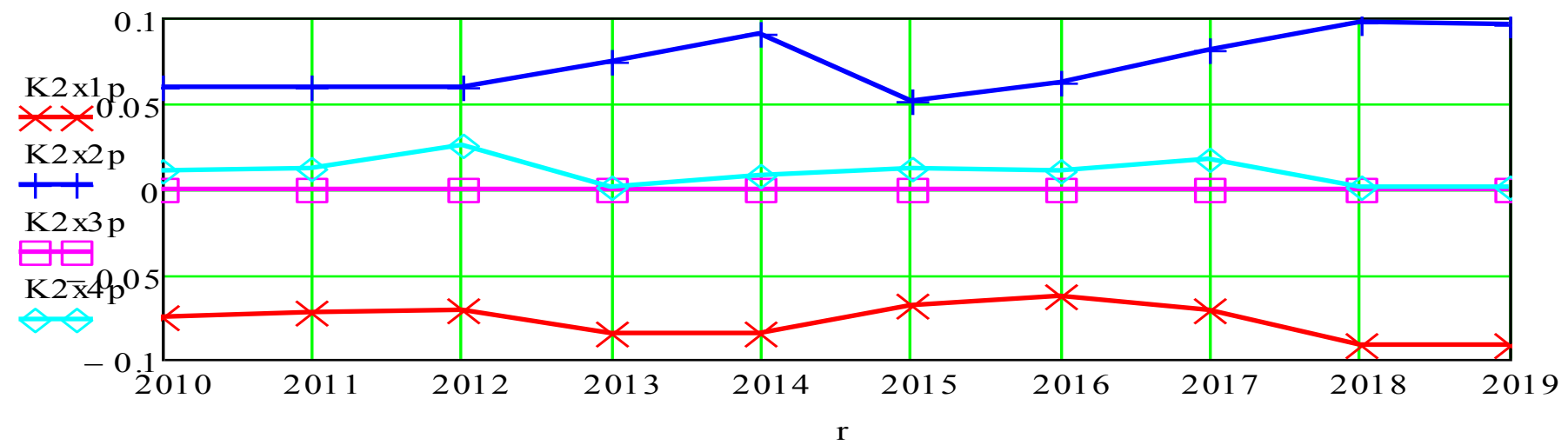

Fig. 10 Visualization of the results of calculations of impact factors for Swiętokrzyskie Voivodeship

Source: calculated by the authors using the Mathcad program

The dynamic changes of the most influential indicator, namely the number of industrial enterprises that have implemented innovations are presented in Figure 11 which shows the dynamic changes in the normalized value until 2020 and the projected values until 2030.

In Figures 12-13 shows the results of forecasting the integrated innovation index of Swiętokrzyskie Voivodeship. In this case, in Figure 12 presents the forecast without taking into account the influence of the most influential indicator, and in Figure 13 taking into account its impact. The difference in the average value between the integrated indices, taking into account the influence of the most influential indicator and without is 0.012 . 


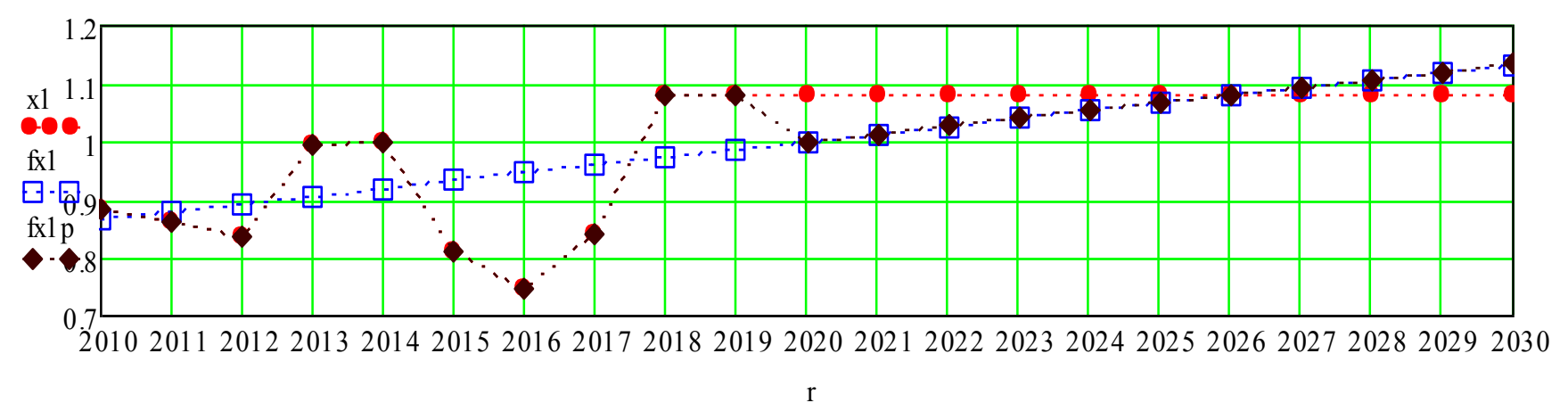

Fig. 11 Visualization of the dynamics of the most influential indicator and its forecast values for Swiętokrzyskie Voivodeship (2010-2019 - retrospective period, 2020-2030 - forecast period) Source: calculated by the authors using the Mathcad program

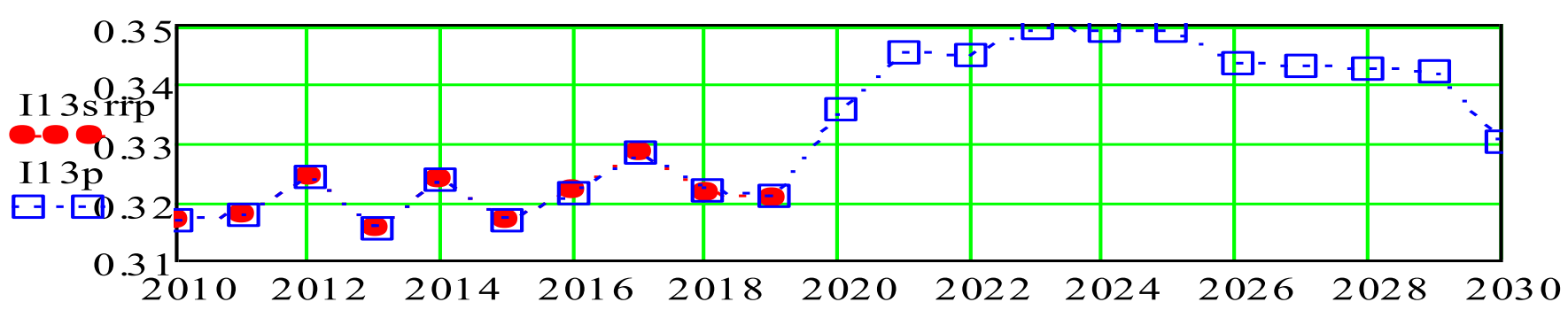

Fig. 12 Visualization of the dynamics of the integrated index and ${ }^{r}$ its forecast values for Swiętokrzyskie Voivodeship (20102019 - retrospective period, 2020-2030 - forecast period)

Source: calculated by the authors using the Mathcad program

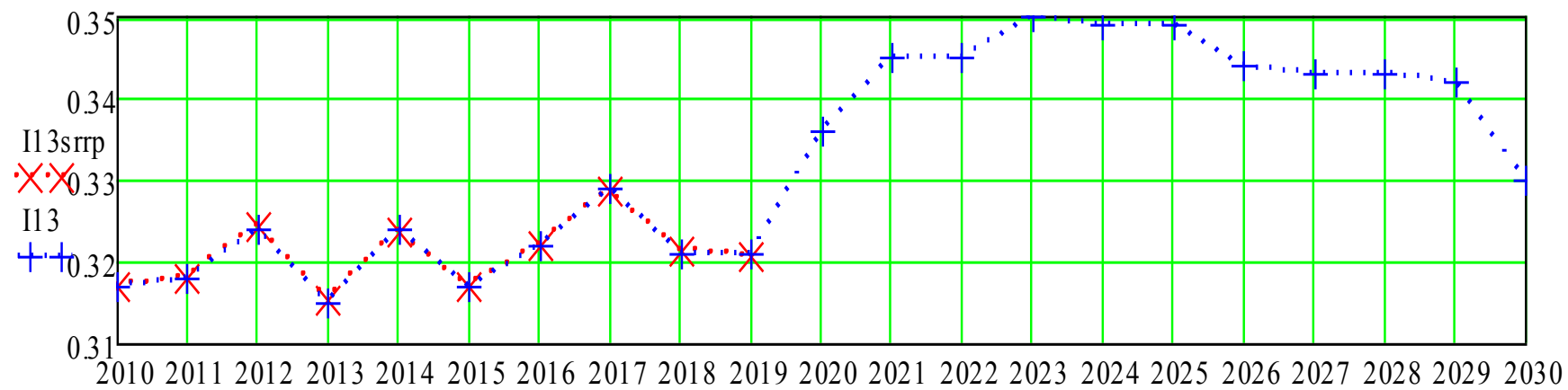

Fig. 13 Visualization of the dynamics of the integrated index and its forecast values for Swiętokrzyskie Voivodeship (20102019 - retrospective period, 2020-2030 - forecast period)

Source: calculated by the authors using the Mathcad program

The proposed methodological approach to forecasting the intensification of innovative development of regions involves the use of the Bartlett method, which provides an approximate approximation of the forecast indicators and several iterations more accurate calculation of the forecast values of the integrated index of regional innovation. It should be noted that all calculations were performed using Mathcad program, builtin forecasting functions which have the calculation of built-in errors, which also has a positive effect on improving the accuracy of forecast values.

\section{V.CONCLUSION}

The conducted research and approbation of the methodical approach of estimation and forecasting of intensification of innovative development of regions with use of the Mathcad software gives the chance to increase accuracy of calculations at the expense of use of such methods and receptions, as:

firstly, to confirm the validity of the selected assessment indicators of innovative development of regions using the method of correlation analysis, which allows to identify and remove autocorrelation relationships between indicators and obtain accurate calculations of integrated indices;

secondly, the use of the multiple regression method to find the most influential indicators on the value of the integrated index of intensification of innovation development;

thirdly, modeling the behavior of changes in regional systems under the influence of changes in the coefficients of 
influence on the value of the integrated index of intensification of innovation development;

fourthly, the use of the Bartlett method and simulation modeling to find forecasting indicators with reduced error and increased accuracy of calculations. The use of the Bartlett method in forecasting makes it possible to approximate the forecast estimates of intensification of innovation development of regions, resulting in adjustment of the initial approximation in the form of iterations, which are repeated, and again calculates the integrated index of intensification of innovation development of regions. As a result of the approximate approximation using the Bartlett method, the initial approximation is adjusted and the forecast integrated indices of intensification of innovative development of the regions are recalculated.

The use of Mathcad software provides high accuracy of predictive values because the correlation analysis of estimates eliminates the possibility of functional relationships between them and provides high accuracy calculations using multiple regressions.

Further research requires the development of methodological principles to improve the management of the intensification of regional development on an innovative basis.

\section{References}

[1] A. Abramova, K. Shaposhnykov, A. Zhavoronok, P. Liutikov, I. Skvirskyi, O. Lukashev, "Ecosystem of VAT Administration in E-Commerce: Case of the Eastern Europe Countries," Estudios de economía aplicada, vol. 39(5), 2021.

[2] R.J.S Arinas, "Regulatory innovation for the circular economy in regional laws," Revista General de Derecho Administrativo, vol. 55, pp. 1-43, 2020.

[3] T.L. Bezrukova, A.T. Gyiazov, A.M. Bazieva, "Modelling and forecasting of innovative development of entrepreneurial structures under the global competition," Actual Problems of Economics, vol. 182(8), pp. 344-351, 2016.

[4] V. Chernova, E. Degtereva, "Forecast of Development of the Dual-Use Industrial Products Market," WSEAS Transactions on Business and Economics, vol. 17, pp. 987-992, 2020.

[5] S. Tulchynska, O. Popelo, O. Vovk, B. Dergaliuk, I Kreidych., T. Tkachenko, "The Resource Supply of Innovation and Investment Strategies of the Microeconomic Systems Modernization in the Conditions of Digitalization," WSEAS TRANSACTIONS on ENVIRONMENT and DEVELOPMENT, vol. 17, pp. 819-828, 2021. DOI: 10.37394/232015.2021.17.77.

[6] S. Shkarlet, M. Dubyna, "Features of the cognitive approach application to the essence of the financial services market identification," Economic Annals-XXI, vol. 158(3-4), pp. 70-74, 2016.

[7] A.A. Firsova, A.P. Tsypin, "Assessment of structural changes in the spatial innovative development of Russian regions," Journal of Physics: Conference Series, vol. 1784(1), 01201, 2021.
[8] O. Popelo, S. Tulchynska, O. Garafonova, L. Kovalska, S. Khanin, "Methodical approach to assessing innovative development efficiency of regional economic systems in the conditions of the creative economy development," WSEAS TRANSACTIONS on ENVIRONMENT and DEVELOPMENT, vol. 17, pp. 685-695, 2021. DOI: 10.37394/232015.2021.17.66.

[9] P. Hajek, R. Henriques, M. Castelli, L Vanneschi, "Forecasting performance of regional innovation systems using semantic-based genetic programming with local search optimizer," Computers and Operations Research, vol. 106, pp. 179-190, 2019.

[10] S. Shkarlet, N. Kholiavko, M. Dubyna, "Territorial reform in the system of strategic management of energyeconomic and information spheres of the state," Economic Annals-XXI, vol. 5-6, pp. 103-107, 2015.

[11]A. Ključnikov, M. Civelek, V. Krajčík, I. Ondrejmišková, "Innovative regional development of the structurally disadvantaged industrial region by means of the local currency," Acta Montanistica Slovaca, vol. 25(2), pp. 224-235, 2020.

[12]I. Kosach, A. Duka, G. Starchenko, O. Myhaylovska, \& A. Zhavoronok, "Socioeconomic viability of public management in the context of European integration processes," Administratie si Management Public, vol. 35, pp. 139-152, 2020.

[13]I. Lazarenko, S. Saloid, S. Tulchynska, S. Kyrychenko, R. Tulchinskiy, "Necessity of implementating data science course in economics curricula," Information technologies and teaching aids, vol. 4(78), p. 132, 2020.

[14]K. Malik, A. Jasińska-Biliczak, "Innovations and other processes as identifiers of contemporary trends in the sustainable development of SMEs: The case of emerging regional economies," Sustainability, vol. 10(5), 1361, 2018.

[15] S. Tulchynska, O. Popelo, V. Marhasova, O. Nusinova, Zh. Zhygalkevych, "Monitoring of the Ecological Condition of Regional Economic Systems in the Context of Sustainable Development," Journal of Environmental Management and Tourism, vol. 12(5), pp. 1220-1228, 2021.

[16] V.P. Nevezhin, A.V. Zhiglyaeva, V.V. Smirnov, N.K. Muravitskaya, "Econometric Models for Forecasting Innovative Development of the Country," Journal of Reviews on Global Economics, vol. 8, pp. 767-775, 2019.

[17] M. Plechero, C. Chaminade, "The role of regional sectoral specialisation on the geography of innovation networks: A comparison between firms located in regions in developed and emerging economies," International Journal of Technological Learning, Innovation and Development, vol. 8(2), pp. 148-171, 2016.

[18] A. Revko, M. Butko, O. Popelo, "Methodology for Assessing the Inflence of Cultural Infrastructure on Regional Development in Poland and Ukraine," Comparatie Economic Research. Central and Eastern Europe, vol. 23(2), pp. 21-39, 2020.

[19] Satya Shah, Keotshepile Mokakangwe, Keitumetes Bose, Sarath Menon, "The Growing Adoption of Internet of 
Things on Supply Chains," International Journal of Economics and Management Systems, vol. 4, pp. 108$112,2019$.

[20] S. Shkarlet, N. Ivanova, O. Popelo, M. Dubina, O. Zhuk, "Infrastructural and Regional Development: Theoretical Aspects and Practical Issues," Studies of Applied Economic, 38(4), 2020.

[21]A.F. Sukhovey, I.M Golova, "Differentiation of innovative development strategies of regions for improving the effectiveness of socio-economic policy in the Russian Federation," Economy of Region, vol. 16(4), pp. 1302-1317, 2020.

[22] Y. Vertakova, I. Risin, Y. Treshchevsky, N. Klimov, "Financial, Institutional and Personnel Threats to Innovative Development of the Region," IOP Conference Series: Materials Science and Engineering, vol. 953(1), 012096, 2020.

[23] A. Viknianska, D. Kharynovych-Yavorska, M. Sahaidak, A. Zhavoronok, V. Filippov, "Methodological approach to economic analysis and control of enterprises under conditions of economic systems transformation," Naukovyi Visnyk Natsionalnoho Hirnychoho Universytetu, vol. 4, pp. 150-157, 2021.

[24] O. Vovk, M. Kravchenko, O. Popelo, S. Tulchynska, M. Derhaliuk, "Modeling the Choice of the Innovation and Investment Strategy for the Implementation of Modernization Potential," WSEAS TRANSACTIONS on SYSTEMS and CONTROL, vol. 16, pp. 430-438, 2021. DOI: $10.37394 / 23203.2021 .16 .38$.

[25] M. Zajkowska, "Open models of innovation processes as a future management challenge for small and medium-sized enterprises in Poland," Journal of Management and Business Administration. Central Europe, vol. 25(4), pp. 193-208, 2017.

[26]N. Kholiavko, A. Zhavoronok, M. Marych, A. Viknianska, S. Kozlovskyi, K. Herasymiuk, "Countries disposition in the global scientific and educational area: management and clustering. International Journal of Management," vol. 11(5), pp. 400-415, 2020.

\section{Creative Commons Attribution License 4.0 (Attribution 4.0 International, CC BY 4.0)}

This article is published under the terms of the Creative Commons Attribution License 4.0

https://creativecommons.org/licenses/by/4.0/deed.en US 